何蕾,李国胜,崔林林,李丽娟,陈艳辉,涂小松.江苏沿海滩涂围垦与社会经济发展的耦合关系.生态学报,2021,41(23):9228-9238.

He L, Li G S, Cui L L, Li L J, Chen Y H, Tu X S.Coupling relationship between reclamation and social economics development in north Jiangsu coastal area. Acta Ecologica Sinica, 2021,41(23):9228-9238.

\title{
江苏沿海滩涂围晆与社会经济发展的堣合关系
}

\author{
何 蕾 $^{1}$, 李国胜 ${ }^{2,3}{ }^{*}$, 崔林林 ${ }^{4}$, 李丽娟 ${ }^{2,3}$, 陈艳辉 ${ }^{2,3}$, 涂小松 ${ }^{1}$ \\ 1 江西财经大学旅游与城市管理学院, 南昌 330013 \\ 2 中国科学院地理科学与资源研究所, 北京 100101 \\ 3 中国科学院大学, 北京 100049 \\ 4 成都信息工程大学, 成都 610225
}

\begin{abstract}
摘要:沿海滩涂湿地是脆弱的生态敏感区, 滩涂围剭是沿海国家和地区拓展土地资源的重要方式之一。近年,沿海地区快速城 市化下的滩涂围剭导致了沿海湿地生态系统退化等一系列环境问题。基于环境库兹涅茨曲线 (Environmental Kuznets Curve, $\mathrm{EKC}$ ) 模型, 以江苏北部沿海湿地为研究区, 结合遥感影像和社会经济数据, 刻画滩涂围剭过程、强度及社会经济发展过程, 揭示 近 40 年江苏沿海滩涂围脣主要类型、阶段性变化特征, 阐述滩涂围屋与社会经济发展的耦合关系。研究结果显示, 养殖水体扩 张是近 40 年江苏滩涂围旺利用的主要方式; 相比养殖水体聚集发展的盐城市, 以启东为典型代表的南通市经历了相对较完整 的养殖水体的滩涂围乍过程, 其养殖水体面积与区域渔业产值存在指数关系, 即当人均地区产值达到约 9.55 万元时, 区域渔业 产值的增长不再以通过围层增加养殖水体面积为主要途径; 从江苏沿海滩涂围垦来看, 滩涂围垦与社会经济发展之间存在典型 倒 U 型曲线关系。苏北滩涂围筀可分为 3 个阶段, 初期阶段 (1980-2005 年), 滩涂围垦随着经济发展而急剧增加; 中期 (2005-2014 年), 当人均 GDP 约为 3.64 $\times 10^{4}$ 元时滩涂围屋速度达最大; 后期 ( $2014-2018$ 年), 滩涂围屋随着经济发展呈现下 降趋势。3 个阶段中, 单位滩涂围垦面积与人均 GDP 增长关系由 4.11 元 $/ \mathrm{km}^{2}, 17.08$ 元 $/ \mathrm{km}^{2}$ 增加至 60.77 元 $/ \mathrm{km}^{2}$, 呈显著增加 的趋势。经济发展,农业和农村经济改革以及国家和地方各级政策均对滩涂围垦具有重要影响。严格的国家环境保护政策将 是有效控制滩涂围剭、保护生态环境的重要手段。
\end{abstract}

关键词: 滩涂围屋;社会经济;耦合关系;苏北

\section{Coupling relationship between reclamation and social economics development in north Jiangsu coastal area}

\author{
HE Lei ${ }^{1}$,LI Guosheng ${ }^{2,3, *}$, CUI Linlin ${ }^{4}$,LI lijuan ${ }^{2,3}$, CHEN Yanhui ${ }^{2,3}$, TU Xiaosong ${ }^{1}$ \\ 1 School of Tourism and Urban Management, Jiangxi University of Finance and Economic, Nanchang 330013, China \\ 2 Institute of Geographic Sciences and Natural Resources Research, Chinese Academy of Science, Beijing 100101, China \\ 3 University of Chinese Academy of Science, Beijing 100049, China \\ 4 Chengdu University of Information Technology, Chengdu 610225, China
}

\begin{abstract}
Tidal flat wetland is one of the most sensitive and fragile ecosystems in the world, and tidal flat reclamation plays an essential role for coastal countries or regions to expand land. In recent years, with rapid urbanization, tidal flat reclamation in coastal areas has led to a series of environmental problems such as wetland ecosystem degradation. Taking coastal wetlands in northern Jiangsu as a research area, based on the Environmental Kuznets Curve (EKC) model, this study attempted to characterize the process of tidal flat reclamation and socio-economic development, and reveal the phase of
\end{abstract}

基金项目: 国家重点研发计划项目资助 (2018YFC0407502);国家自然科学基金 (41901130)

收稿日期:2020-07-16; 采用日期:2021-05-10

*通讯作者 Corresponding author.E-mail: ligs@ igsnrr.ac.cn 
reclamation over the past 40 years, and explain the coupling relationship between tidal flat reclamation and social economic development. The results showed that the expansion of aquaculture water has been the main characteristics of reclamation in Jiangsu tidal flats in the past 40 years. Compared with Yancheng City, where aquaculture water bodies are clustered developing, Nantong City, which is represented by Qidong, has experienced a relatively complete tidal flat reclamation process for aquaculture water bodies. An exponential relationship was observed between the area of aquaculture water bodies and the regional fishery output value in Qidong, that is, when the per capita regional output value reached approximately 95,500 Yuan, the increase of regional fishery output value no longer depended on increasing the aquaculture water area through reclamation. There was a typical inverted $U$ curve relationship between tidal flat reclamation and economic development in north Jiangsu coastal area in the past 40 years. The process of reclamation in north Jiangsu coastal area can be divided into three phases. In the early phase (1980-2005), the reclamation increased sharply with economic growth. In the middle phase (2005-2014), the increasing trends of reclamation and economic growth continued, with a turning point appeared, when the per capita GDP was about $3.64 \times 10^{4}$ Yuan, and the maximum reclamation appeared with the speed up to $146.34 \mathrm{~km}^{2} / \mathrm{a}$. In the late phase $(2014-2018)$, tidal flat reclamation showed a downward trend while the economy still increasing. In the three stages, the relationship between reclamation and per capita GDP growth increased from 4.11 Yuan/ $\mathrm{km}^{2}$ and $17.08 \mathrm{Yuan} / \mathrm{km}^{2}$ to $60.77 \mathrm{Yuan} / \mathrm{km}^{2}$, showing a significant growing trend. Economic development, agricultural and rural economic reforms, and national and local policies make important impacts on tidal flat reclamation. The strictly national environmental protection policies would be of great significance to effectively control tidal flat reclamation and protect the coastal ecological environment.

Key Words : reclamation; social economics; coupling relationship; north Jiangsu coastal area

沿海滩涂湿地位于陆地生态系统和海洋生态系统的过渡地带, 是脆弱的生态敏感区, 也是重要的环境资 源, 滩涂围屋是世界各国, 尤其是沿海土地资源不足的国家和地区拓展土地资源的重要方式 ${ }^{[1]}$ 。近几十年, 作为人类居住和经济活动的重要枢纽, 沿海地区经历了快速城市化和过度开垦等一系列高强度发展, 导致其 景观结构和生态功能发生了急剧甚至不可逆转的变化 ${ }^{[2-4]}$ 。滩涂围垦造成的湿地面积损失或景观类型转换 是沿海地区生态系统发生的最显著和易感知的变化之一 ${ }^{[5]}$ 。自 1990 年以来, 全球超过 $50 \%$ 的自然湿地已经 消失 ${ }^{[6]}$ 。湿地面积减少和退化引发了一系列环境和生态问题,包括栖息地破坏、土壤退化和生物多样性丧失 等 ${ }^{[7-9]}$ 。因此,理清社会经济快速发展下, 沿海湿地对社会经济发展的响应及其机制是亟需深人开展的内容, 研究将有助于理解沿海滩涂将来是否仍能保持功能和提供服务, 以及可以采取哪些干预措施来维持其功能或 抑制其面积减少 ${ }^{[10-11]}$ 。

影响滩涂围层的因素主要可以概括为两方面 ${ }^{[12]}$ 。一方面,社会经济发展过程中,生产和提供人类活动所 需的资源以及承载空间决定了滩涂围层的类型和速度, 例如, 快速大量的人口增长需要更多居民楼和基础设 施的扩建 ${ }^{[13]}$; 另一方面, 国家和地方各级土地利用规划等政策和相关法律文件及执行力度已被认为是影响湿 地变化的重要驱动力 ${ }^{[14]}$ 。随着沿海地区高度人口聚集和城市化发展, 越来越多的国家和地区意识到追求发 展不能再以牺牲环境为代价, 进而制定采取了一系列生态资源保护战略和措施。平衡经济发展与环境保护是 多年以来国内外众多研究的核心问题, 并取得了大量研究成果, 然而目前较多研究集中在揭示沿海湿地景观 变化,指示环境因子的变化等, 而对于经济发展与滩涂围艮强度的关系, 以及相应政策和法规的影响研究尚待 加强 ${ }^{[15-19]}$ 。

江苏沿海滩涂湿地是中国乃至世界为数不多的典型原始海岸湿地之一,基本保持了天然的生态结构和功 能。然而近年, 随着江苏沿海开发战略的落实, 沿海地区开发强度增大, 海岸湿地景观发生巨大变化 ${ }^{[20-22] 。}$ 《江苏省沿海地区发展规划》(2009) 提出至 2020 年,通过对盐城射阳河口至南通东灶港之间的大丰、东台、如 东、启东海岸和琼港外的辐射沙洲等地围填,形成约 18 万 $\mathrm{hm}^{2}$ 后备资源土地。江苏沿海地区以每年约 $20-$ 
$200 \mathrm{~m}$ 的速度不断向海域扩张, 也由此导致了一系列严重的环境问题, 滩涂生态系统的功能受到威胁, 沿海滩 涂湿地保护与开发利用的矛盾进一步加大 ${ }^{[23-26]}$ 。在此背景下,本研究拟通过建立江苏滩涂围剭与社会经济 的相互关系,开展湿地生态系统与社会经济耦合机制研究,为湿地生态系统保护、利用开发和管理提供依据。

\section{1 研究区概况}

江苏沿海滩涂位于中国江苏省北部,黄海以东,面积约为 $50 \times 10^{5} \mathrm{hm}^{2}$,约占中国沿海地区的 $25 \%$,拥有丰 富的滩涂资源。江苏沿海滩涂开发历史悠久, 其土地利用变化受自然和人类活动双重因素驱动, 经历了以兴 海煮盐、旺荒植棉、围海养殖、临海工业等为主要利用方式的多个阶段,进行了较大规模的滩涂围层开发活 动 ${ }^{[27-28]}$ 。本研究选取了涉及盐城市 (主要涉及响水, 滨海, 射阳, 大丰, 东台等五县市) 和南通市 (主要涉及海 安, 如东, 通州, 海门和启东等五县市) 等两市共十个县(市) 行政区域的沿海滩涂区 $\left(119^{\circ} 28^{\prime}-121^{\circ} 58^{\prime} \mathrm{E}\right.$, $31^{\circ} 40^{\prime}-34^{\circ} 32^{\prime} \mathrm{N}$ ) 作为研究区域 (苏北滩涂区) (图 1)。

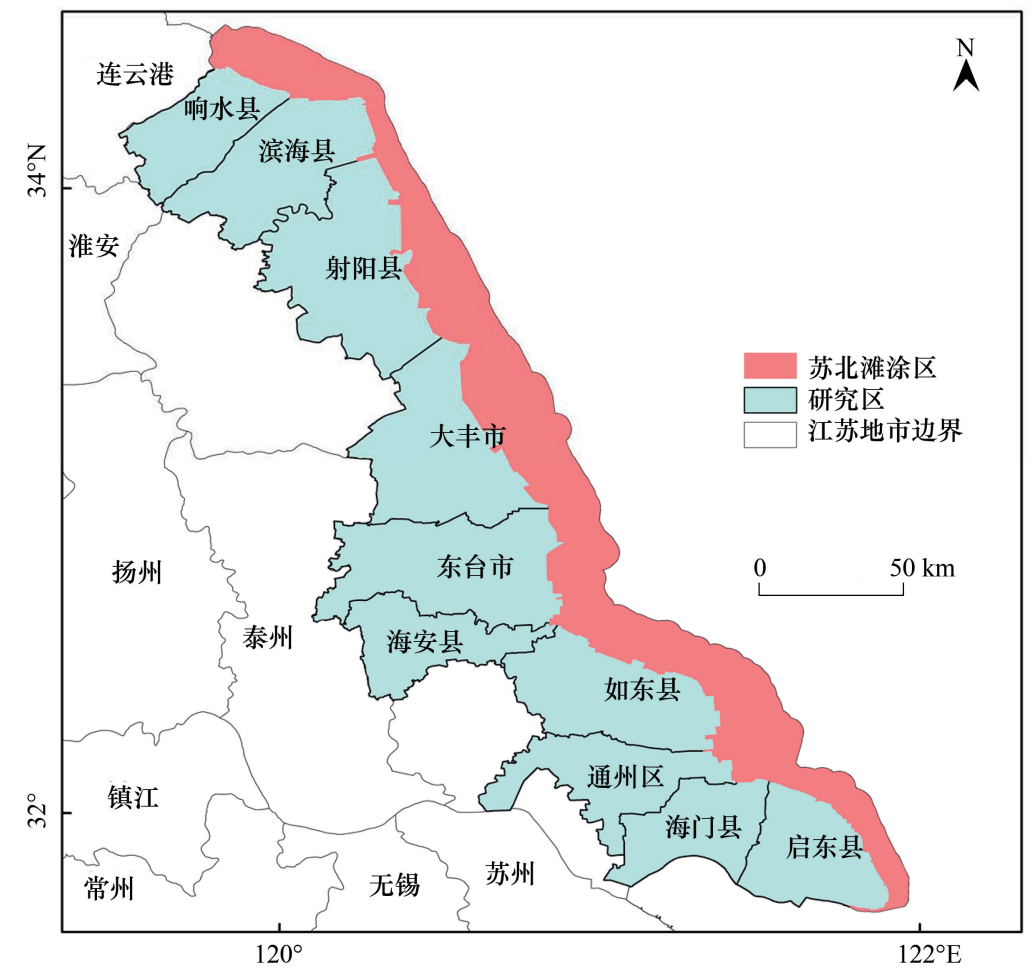

图 1 研究区地理位置

Fig.1 Location of the study area

\section{2 数据收集与处理}

遥感数据是用于研究区域景观变化的有利支撑。覆盖江苏省海岸需要三景 Landsat 影像数据, 由于三景 影像分别位于 3 个相邻的卫星轨道上, 难以保证它们成像时间完全一致 ${ }^{[29]}$ 。同时,考虑到江苏省海岸线的特 点、数据本身的问题 (如云覆盖、成像质量等) 和数据的可获取性, 本研究从美国地质调查局 (http://www. usgs. gov/) 收集了 1979 年至 2018 年覆盖研究区的共 32 景遥感影像 (表 1)。这些影像大致可概括为位于 1980 、 $1983 、 1986 、 1992 、 1995 、 2000 、 2005 、 2008 、 2010 、 2014$ 和 2018 年共 11 个时间点, 较均匀地将整个研究期划分为 10 个阶段。研究对影像进行了系统的辐射校正, 地面控制点的几何校正和数字高程模型的地形校正, 重新投 影到通用 UTM 投影。 
表 1 研究收集的影像数据

Table 1 List of Landsat images used in this study

\begin{tabular}{|c|c|c|c|}
\hline $\begin{array}{l}\text { 影像日期 } \\
\text { Date }\end{array}$ & $\begin{array}{l}\text { 传感器 } \\
\text { Sensor }\end{array}$ & $\begin{array}{c}\text { 分辨率 } \\
\text { Resolution }\end{array}$ & $\begin{array}{l}\text { 轨道号 } \\
\text { Path/Row }\end{array}$ \\
\hline $19790910 、 19810908$ & MSS & $80 \mathrm{~m}$ & $129 *-36$ \\
\hline $\begin{array}{l}19830801 、 19870921 、 19910831 、 19950927 、 19991008 、 20060909 、 \\
20091003 、 20110603 、 20150918 、 20180419\end{array}$ & TM/ETM+/OLI & $30 \mathrm{~m}$ & $120-36$ \\
\hline $\begin{array}{l}19840423 、 19860819 、 19930603 、 19950812 、 19990924 、 20050503 、 \\
20090919 、 20110808 、 20130829 、 20160720\end{array}$ & TM/ETM+/OLI & $30 \mathrm{~m}$ & $118-38$ \\
\hline $\begin{array}{l}19840804 、 19850924 、 19920607 、 19960805 、 20000917 、 20060918 、 \\
20080502 、 20110815 、 20151013 、 20180428\end{array}$ & TM/ETM+/OLI & $30 \mathrm{~m}$ & $119-37$ \\
\hline
\end{tabular}

*1979、1981 年的 MSS 影像,轨道号 129 对应于现在的 120

社会经济统计数据包括近 40 年的人口数据和国内生产总值(GDP), 研究区渔业产值及农业总产值等, 均来自以上十个行政区和江苏省的历年统计年鉴。根据通货膨胀或通货紧缩的价格变化对 GDP 进行校正, 依据国家零售价格指数校正到 2018 年的统一水平。

研究采用监督分类对研究区影像进行分类处理,生成土地利用/土地覆盖 ( LUCC) 分类图。采用最大似 然法进行分类, 根据先验知识识别确定每个类别的训练点, 通过训练点对图像中的像素进行训练和分类, 结合 实地考察获得的地面真实数据以及基于历史调查图和 Google Earth 的高分辨率影像对图像进行解译。江苏 沿海滩涂主要包括 15 个类别,可归纳为 3 个主要类别: (1) 天然湿地: 草甸、芦苇、互花米草、盐蒿、河流、潮间 带光滩; (2) 人工湿地: 水田、盐田、养殖水体、水库坑塘; (3) 非湿地: 旱地、堤防、建设用地、森林和裸地。分类 结果的准确性评估表明,Kappa 一致性指数为 0.85 ,总体一致性为 $90 \%$,说明影像分类精度较高。

滩涂围虎可被理解为满足人类生存或社会或经济目的对天然湿地的占用,并从农业或其他土地利用类型 中获利的工程。因此,根据占用用途不同,本研究中包括自然湿地转为人工湿地和自然/人工湿地转为非湿地 的类型变化均被归纳为滩涂围垦。其中,其他类别地类向裸地的转化没有被考虑, 因为该过程被认为不是直 接出于社会或经济获益目的。

\section{3 研究方法}

研究拟采用环境库兹涅茨曲线 (Environmental Kuznets Curve,EKC) 刻画近 40 年滩涂围层与社会经济发 展的关系。EKC 是一种经验假说, 假定社会经济发展与环境质量之间存在关系, 即环境退化或资源使用被认 为发生在低水平的经济增长阶段,然后达到顶峰(转折点)。此后,在经济持续增长的同时,资源使用将减少 或环境质量得到改善,即经济增长与环境退化或资源使用之间存在倒 $U$ 型关系 ${ }^{\left[{ }^{30]}\right.}$ : 在经济发展的早期阶段, 人们通过消耗更多的资源而获得经济增长, 人们更加关注收人而不是环境, 导致资源消耗增加或环境质量下 降。随着经济的繁荣,人们意识到空气和水等环境质量的重要性,由此制定了更加严格的环境法规等进行资 源开采限制或环境保护。同时,加上社会经济的结构变化和技术创新, 此后的经济增长将逐渐消耗更少的资 源或环境质量得到提升。众多研究使用各种社会经济和环境变量对 $\mathrm{EKC}$ 模型进行了调整并验证了这种假 说, 主要变量包括能源消耗, 人口密度,政治因素, $\mathrm{CO}_{2}$ 排放,归一化植被指数 (NDVI) 和森林砍伐等 ${ }^{[31-34]}$ 。滩 涂围层代表了资源消耗的一个关键方面,但在 EKC 模型框架中相关研究较少,因此,本研究采用 EKC 模型刻 画江苏滩涂湿地围剭与社会经济发展水平关系 ${ }^{[35]}$, 以期为沿海城市发展与资源保护提供理论支撑基础和借 鉴经验。

本研究中采用研究区所涉及各区县人均 GDP 作为表征经济发展水平的自变量; 因变量是各区县滩涂围 垦规模。一般地考虑用滩涂围良面积表征规模大小, 即自然/人工湿地转变为非湿地或自然湿地转变为人工 湿地的面积。但由于研究区所涉及的各行政区域面积大小不同,滩涂围层面积也可能有较大差异,为统一基 准,将每个行政区涉及的滩涂围垦占该行政区面积的比例作为滩涂围旺规模,即在模型中用作解释变量来表 征环境退化。经济发展与滩涂围垦之间的关系不是单调变化的,而是随着时间的流逝可能呈现出不同的形 
状。可使用线性或二次函数来描述二者复杂的关系, 或使用自然对数转换对变量进行预处理 ${ }^{[36]}$, 这也将有效 地刻画经济发展与环境要素之间的关系。因此,EKC 可以表达为:

$$
L_{t}=\alpha+\beta_{1} E_{t}^{2}+\beta_{2} E_{t}+\varepsilon
$$

或

$$
\ln L_{t}=\alpha+\beta_{1}\left(\ln E_{t}\right)^{2}+\beta_{2} \ln E_{t}+\varepsilon
$$

式中, $L$ 代表滩涂围垦规模; $E$ 代表经济指标 (即人均 GDP); $t$ 表示时间段,而 $\varepsilon$ 是随机误差项 ${ }^{[37]}$ 。参数 $\beta_{1}$ 和 $\beta_{2}$ 定义了经济发展与滩涂围垦的函数关系的形式,这取决于一定时期内经济发展对滩涂围层的影响。一般 地, 当 $\mathrm{EKC}$ 关系存在时, $\beta_{1}$ 的符号为负, 即曲线呈倒 U 型。

\section{4 结果}

4.1 江苏沿海土地利用/土地覆盖变化

图 2 为 1980-2018 年期间江苏沿海滩涂土地利用/土地覆盖变化( LUCC) 结果。其显著趋势是图中研究 区主要颜色自 1990-2018 年逐渐从蓝色和绿色变为紫色和红色, 即光滩等天然湿地向养殖水体和建设用地 转化。

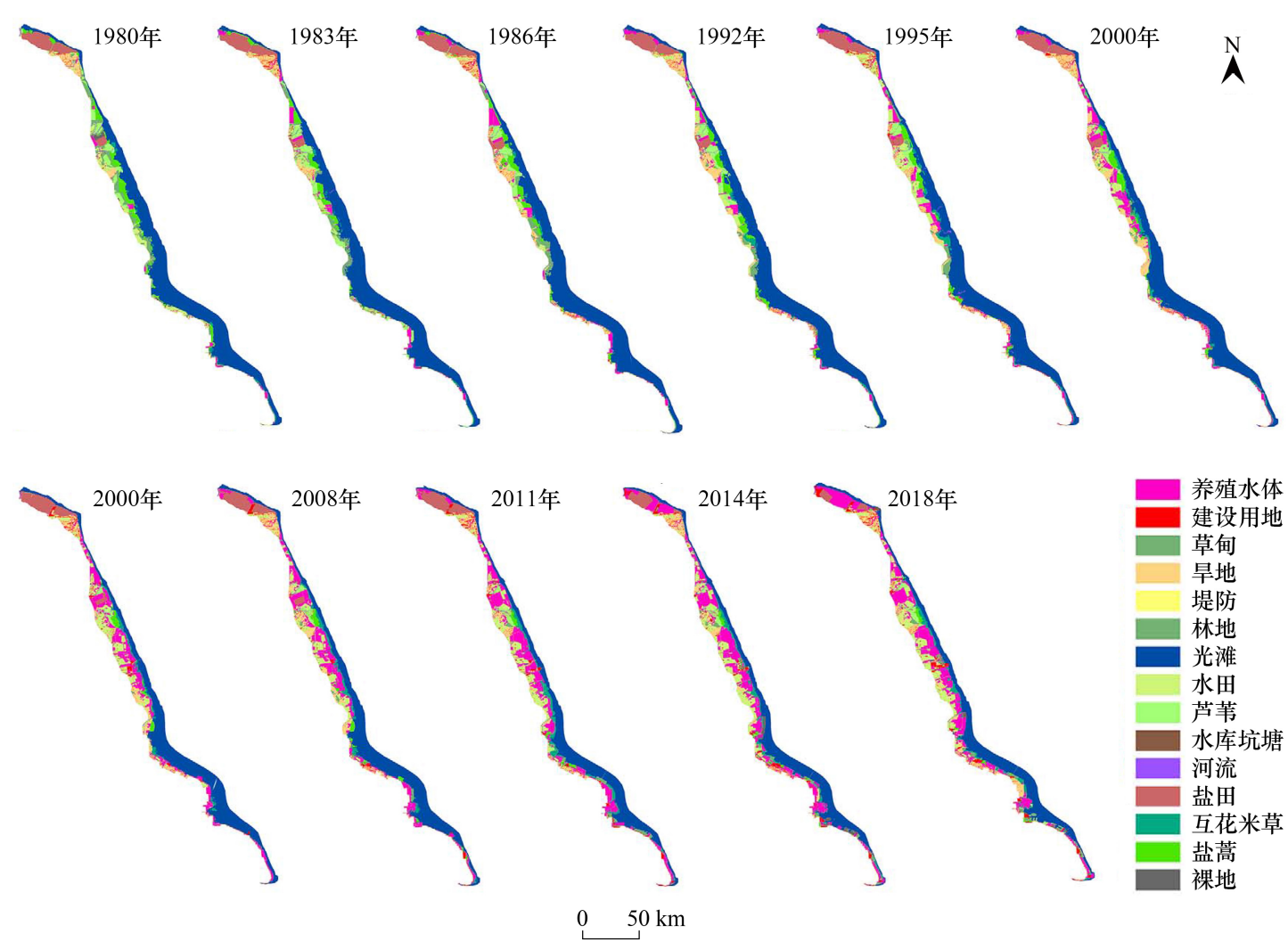

图 2 研究区 1980-2018 年土地利用/土地覆盖状况

Fig.2 Land use and land cover change in the study area from 1980 to 2018

1980 年, 研究区以光滩为主, 面积最大 (占研究区总面积 55.18\%), 主要集中在射阳县以南沿海地带, 包 括射阳、大丰、东台、如东、启东等区县沿海区域; 其次是占据紧邻光滩向内陆方向位置的盐蒿 (占总面积 $7.87 \%$ ) 以及分布于研究区上部主要涉及响水和滨海县的盐田 (占总面积 7.58\%)。覆盖率达 7.02\% 的草甸主 要分布在盐蒿的西边, 即更靠近陆地方向。水田, 芦苇, 旱地和养殖水体分别占滩涂总面积 5.88\%, 5.19\%, $3.69 \%$ 和 $1.58 \%$ 。 
对比 1980 和 2018 年 (图 2), 江苏沿海滩涂最显著的变化是养殖水体的增加和光滩的减少。从 1980 年 到 2018 年, 养殖水体面积增加了 $1694.54 \mathrm{~km}^{2}$, 约占滩涂总面积 $24.14 \%$, 平均每年增加约 $43.45 \mathrm{~km}^{2}$ 。养殖水 体的增加主要来自于光滩围垦: 至 2018 年, 大约 $44.88 \%\left(793.79 \mathrm{~km}^{2}\right)$ 的养殖水体来自于光滩转换, $20 \%$ 来自 盐田 (356.35 $\mathrm{km}^{2}$ ), 约 $12.16 \%$ 来自于盐蒿(约 $215.12 \mathrm{~km}^{2}$ )。而近 40 年, 光滩面积减少了 $22.86 \%$ ( 1603.18 $\left.\mathrm{km}^{2}\right)$ 。大部分消失的光滩被转化为养殖水体 $(49.51 \%)$, 分别约有 $17.52 \%$ 和 $8.7 \%$ 被转化为互花米草和草甸。

\section{2 滩涂围圼与社会经济发展}

\subsection{1 围旺面积与社会经济发展}

为进一步研究滩涂围层与社会经济的关系,依本研究关于滩涂围层的理解,将地类小类分别归纳至天然 湿地、人工湿地和非湿地,进一步分析其围圼规律和过程。过去 40 年,随着社会经济发展,研究区大量自然湿 地被围屋为人工湿地或非湿地, 或者人工湿地被转为非湿地。天然湿地的比例从 1980 年的 $77.56 \%$ 逐渐减少 到 2018 年的 $44.41 \%$, 而人工湿地的比例从 $15.76 \%$ 逐渐增加至 $35.66 \%$ 。天然湿地的减少主要是光滩的围屋 所致,而人工湿地的增加则是由于养殖水体的扩大(图 2)。这是过去 40 年江苏沿海地区湿地生态景观的主 要变化特征。此外,非湿地所占比例虽然增加微弱,但仍呈稳定增长的趋势。这主要是由于该期间的建设用 地和旱地面积扩大所致,近 40 年,它们分别增长了 $857.12 \%$ 和 $145.82 \%$ 。

尽管如图 3 所示, 过去 40 年中, 研究区天然湿地、人工湿地和非湿地面积变化较为平稳, 但其滩涂总围良 面积呈现出高低振荡波动(图 4)。湿地围层面积在 20 世纪 80 年代初从 $126.17 \mathrm{~km}^{2}$ 增加到 $375 \mathrm{~km}^{2}$, 然后在 20 世纪 90 年代初下降到 $217.92 \mathrm{~km}^{2}$ 。1980-1992 年间, 滩涂围层速度较低, 大约为 $59.99 \mathrm{~km}^{2} / \mathrm{a} 。$ 在 $1992-$ 2005 年期间, 围剭速度急剧增加, 大约为 $261.87 \mathrm{~km}^{2} / \mathrm{a}$ 。此后一直下降到 2011 年, 继而在 2014 年达到另一个 小的高峰。在 2014-2018 年,滩涂围剭速度再次放缓。2008-2018 年的滩涂围剭速度约为 $128.51 \mathrm{~km}^{2} / \mathrm{a}$ 。 与此同时, 江苏沿海地区的 GDP 呈指数增长, 尤其自 1992 年后, GDP 曲线斜率增大; 而人口相对稳定, 直到 2014-2018 年,平均人口与 1980-2014 早期相比,增长了 31.33\%。

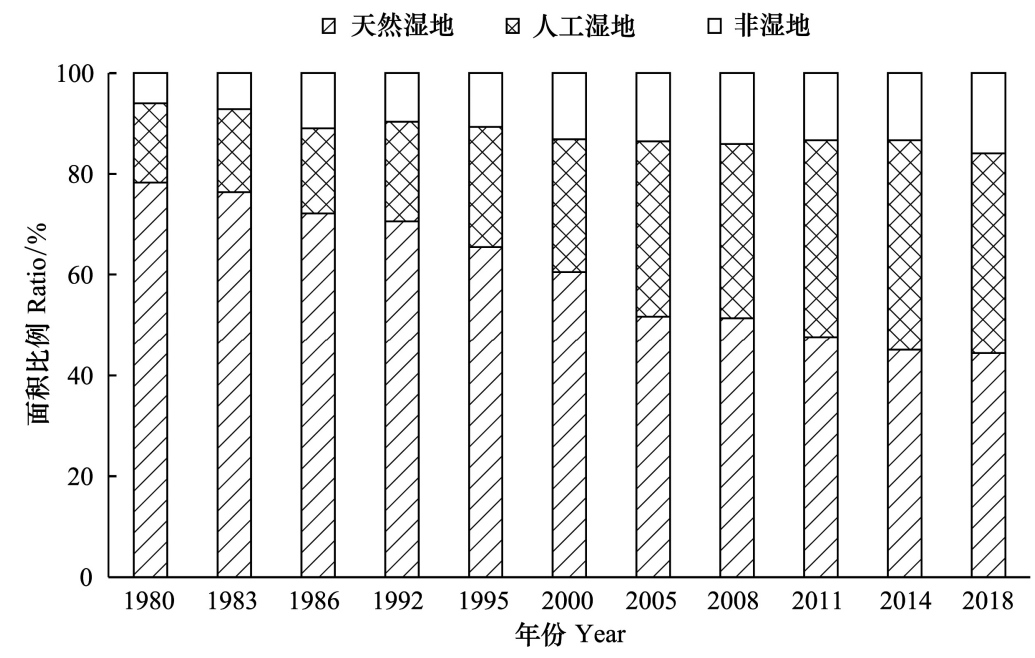

图 3 研究区 1980一2018 年天然湿地、人工湿地和非湿地面积占比

Fig.3 Comparison of area covered by natural wetland, artificial wetland or non-wetland during 1980 to 2018

\subsection{2 围剭类型与社会经济发展}

养殖水体是近 40 年江苏沿海滩涂围层的主要方向之一, 且从相对较均匀地分布在盐城市 (约占总养殖水 体面积 $57.13 \%$ ) 和南通市 (约占总养殖水体面积 $42.87 \%$ ) 沿海滩涂, 发展形成了以盐城市的射阳为核心 (盐 城市养殖水体面积占江苏沿海滩涂养殖水体总面积约 $83.06 \%$ ), 以及部分分布在南通市的启东县 (占江苏省 滩涂养殖水体总面积约 $11.06 \%$ ) 的相对集聚的格局。 
通过比较研究区各市县历年渔业占农业总产值的 比值 (图 5) 可以看出, 过去 40 年江苏沿海市县渔业发 展具有不同特征。盐城市射阳县自 1992 年起其渔业产 出占农业总产值约 $25 \%$ 左右, 相较其它市县, 是渔业产 出大县; 南通市大丰、启东及如东县渔业占农业总产值 的比重自 1992 年后呈显著增长趋势 (图 5)。这与 20 世纪 80 年代末 90 年代初,江苏政府大力推进农业结构 调整, 由传统的种植业向综合农业发展, 倡导渔业是农 业资源综合开发的主体产业等政策密不可分。而随着 生活水平的提高, 对水产品的消费依赖提升及过度捕捞 等压力进一步促进了养殖产业的发展, 20 世纪 90 年代 初, 江苏养殖产品产值首次超过野生捕捞产值。相比较 渔业产值占比变化趋势不甚明显的盐城市, 南通市渔业

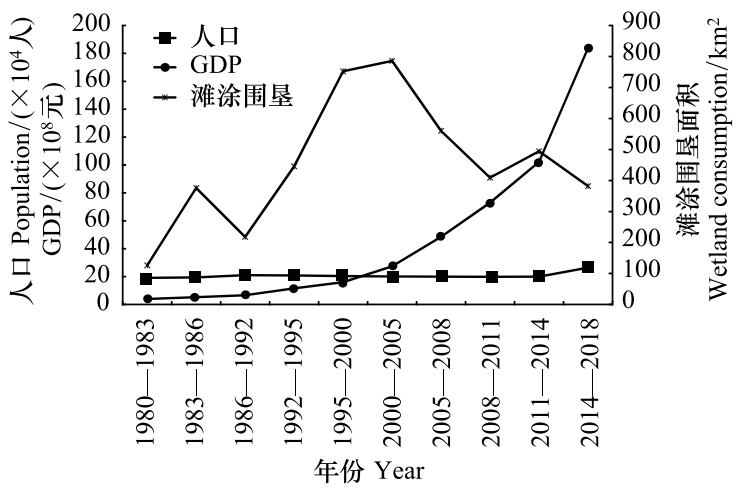

图 4 研究区 $1980-2018$ 年人口、GDP 和滩涂围旺面积变化

Fig.4 Changes of population, GDP and reclamation area from 1980 to 2018 产值占农业总产值比重变化 (图 5) 较为一致, 启东、如东、海门及通州均在 2005 年左右达到波峰,此后逐步下 降。这与“十一五”及“十二五”期间,南通市沿海围垦以发展临港工业, 围垦面积主要用于港口、能源、化工、 物流、城镇和生态旅游等建设用地,进人了一个以增加工业用地为主的新阶段有关。
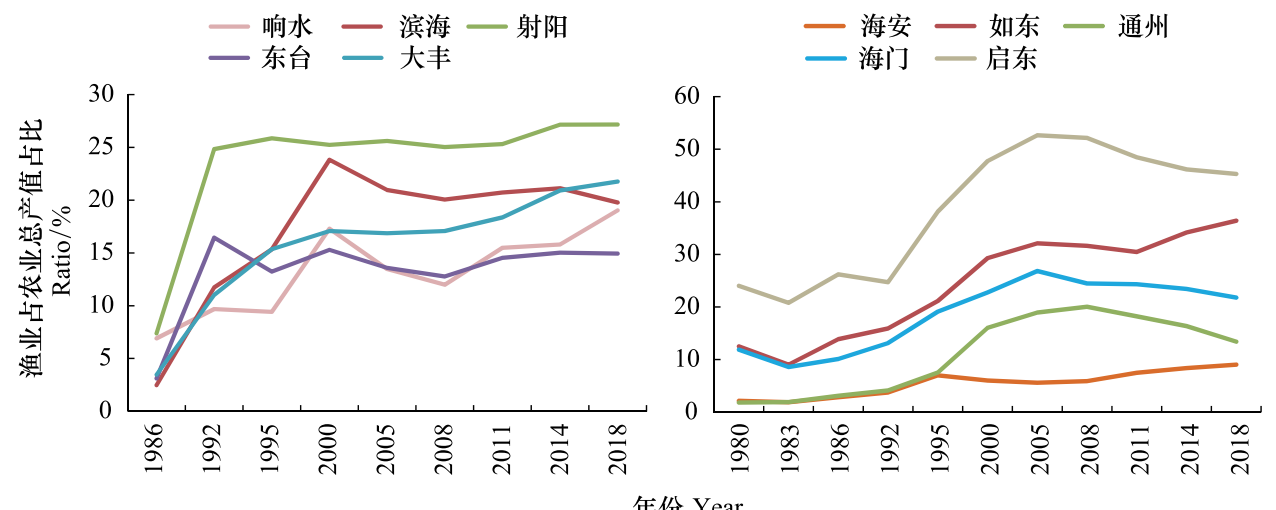

图 5 研究区各市县 1980-2018 年渔业产值占农业总产值比重

Fig.5 Proportion of fishery output value in the total agricultural output value of each city/county in the study area from 1980 to 2018

经济结构转型促进了研究区滩涂地区围层方式的转换。为比较不同滩涂占用状况及社会经济发展的关 系, 研究分别选取了养殖水体围垦发展历程较完整的典型代表启东县, 以及研究区整个滩涂区域的养殖水体 面积及相应渔业产值进行拟合, 结果显示 (图 6), 过去 40 年江苏沿海滩涂渔业产值与养殖水体面积存在较好 的线性关系, 目前阶段, 渔业产值与养殖水体面积存在线性增长。说明在整个江苏沿海滩涂, 渔业产值增加仍 主要依赖于养殖水体面积的扩大。而启东县养殖水体面积与区域渔业产值呈现显著的对数关系 (图 6), 即渔 业产值较低时, 养殖水体面积也较小, 而后二者急剧增长, 当渔业产值达到一定值 (如启东县渔业产值为 65 . 58 亿元, 此时人均地区生产总值 9.55 万元), 养殖水体的面积不再增长, 即此后该区域渔业产值的增长不再 以通过围脣增加养殖水体面积为主要实现方式。

\subsection{EKC 拟合结果与分析}

选择适宜的指标因素建立经验模型是研究社会经济发展与湿地围脣之间关系的关键。本研究将研究区 各行政区域涉及的滩涂围屋占该行政区面积的比率作为 EKC 模型的环境指标,并将相应的人均 GDP 作为经 济变量。考虑到经济数据的偏斜分布,对人均 GDP 和滩涂围垦比率采用自然对数转换。这两个变量的相关 系数为 $0.47(\alpha=0.01)$ 。 


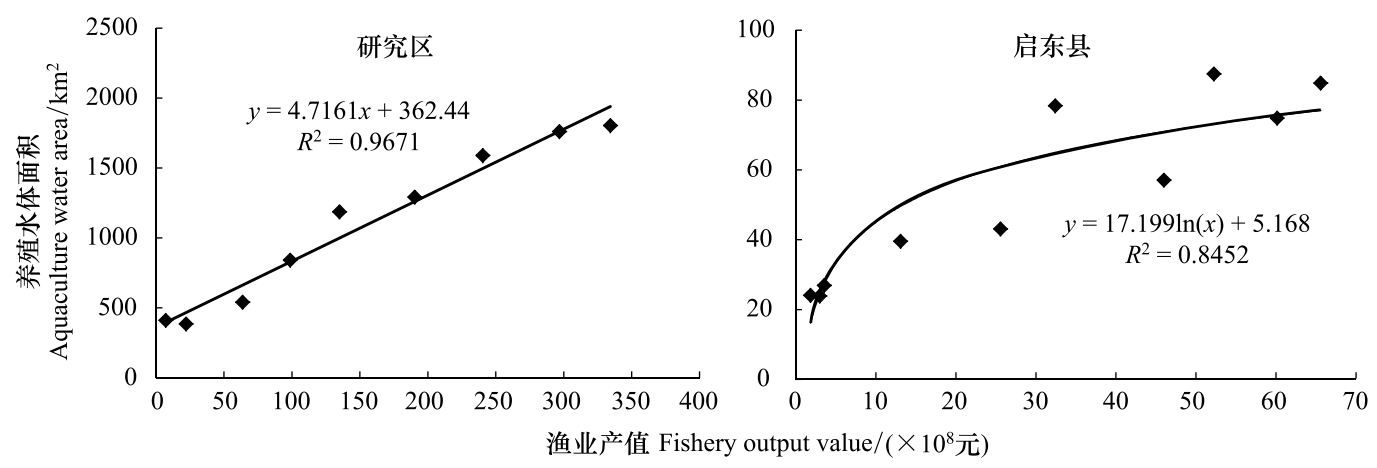

图 6 研究区及启东县养殖水体面积与渔业产值关系

Fig.6 The relationship between the aquaculture water area and fishery output value in the study area and Qidong County

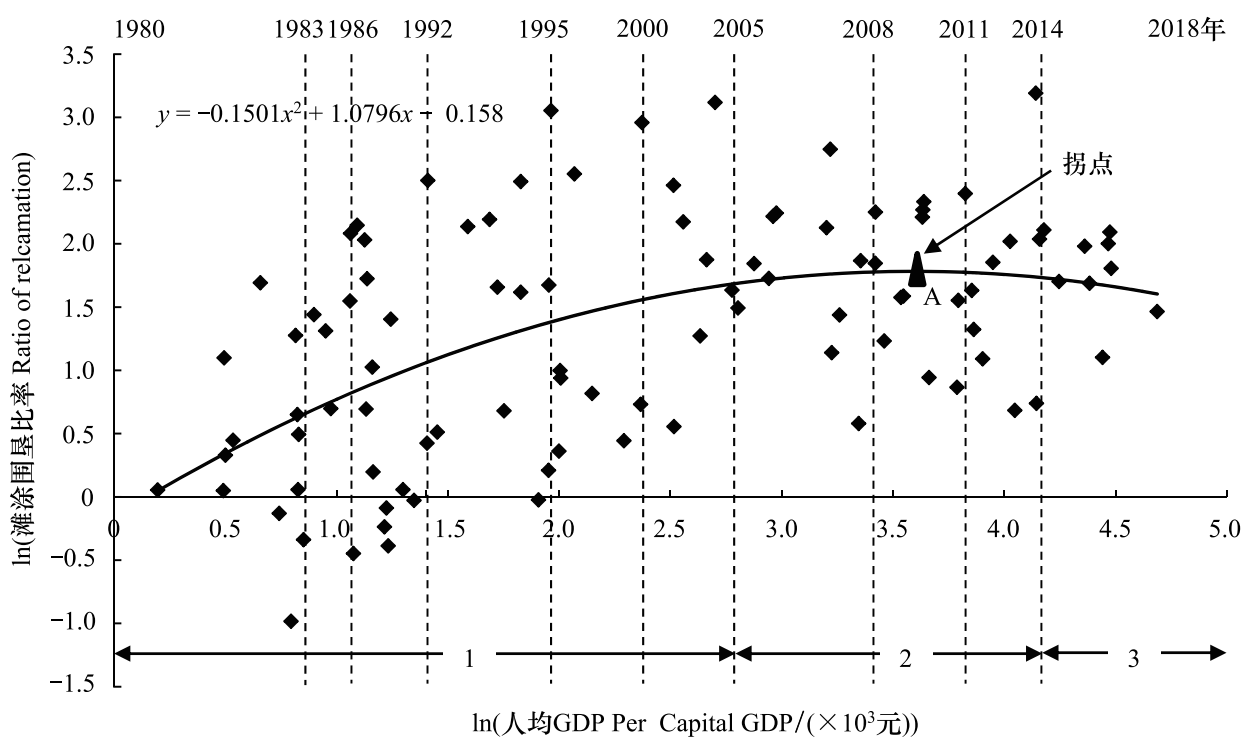

图 $7 \quad 1980-2018$ 年苏北滩涂围旺与社会经济发展的关系

Fig.7 Relationship of reclamation and economic development between 1980 to 2018 in north Jiangsu coastal area

本研究对经过处理后的经济发展指标和滩涂围剭指标进行拟合,二者呈现典型的 $\mathrm{EKC}$ 模式 (图 7 )。根 据人口和 GPD 统计测算得出人均 GDP 水平,并据此对应标记出 11 个时间点,即 10 个区间。由图中可知, 江 苏沿海滩涂围层可以大致分为 3 个阶段。早期阶段,即图 7 中的第一阶段 (1980-2005 年),滩涂围怎随着经 济发展而急剧增加。在此期间,沿海地区的人均 GDP 不到 $1.7 \times 10^{4}$ 元, 滩涂围层速度约为 $108.13 \mathrm{~km}^{2} / \mathrm{a}$, 此时 滩涂围垦与人均 GDP 增长的关系为 4.11 元 $/ \mathrm{km}^{2}$ 。随着人均 GDP 增长, 滩涂围怎规模达到顶峰, 即在图 7 的 第二阶段 (2005-2014 年), 拟合曲线的斜率变为相对平坦, 不像早期陡峭。围剭的最大值(曲线上的 A 点)

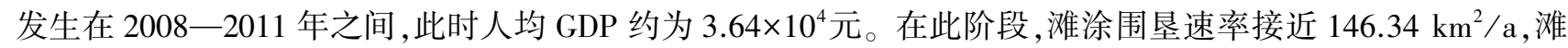
涂围层与人均 GDP 增长的关系为 17.08 元 $/ \mathrm{km}^{2}$ 。A 点通常称为拐点, 到达 $\mathrm{A}$ 点之后, 滩涂围虎与经济发展之 间的关系发生变化, 即滩涂围垦速度不再随人均 GDP 增长而增加, 反而呈现下降趋势。第三阶段 (2014一 2018 年), 随着社会经济的发展, 江苏人均 GDP 高达 $7.37 \times 10^{4}$ 元, 围剭速率约为 $76.35 \mathrm{~km}^{2} / \mathrm{a}$, 单位滩涂围层与 人均 GDP 增长的关系增加至 60.77 元 $\mathrm{km}^{2}$ 。此外, 可以很清楚地注意到, 人均 GDP 与滩涂围层之间的关系 不是一个完美的倒 U 形, 曲线的右侧似乎还未完结。这表明, 随着人均 GDP 的增长, 滩涂围旺下降的趋势有 望继续发展。 


\section{5 讨论}

\section{1 主要社会经济因素影响}

在探明 $\mathrm{EKC}$ 的假设基础时,涉及许多因素,例如农业,农村经济结构,政策和文化偏好等。苏北沿海滩涂 围垦历史悠久, 在 1980 年代之前, 沿海开垦以盐业和农业为主导, 自 1980 年代以来, 该地区以水产养殖为主

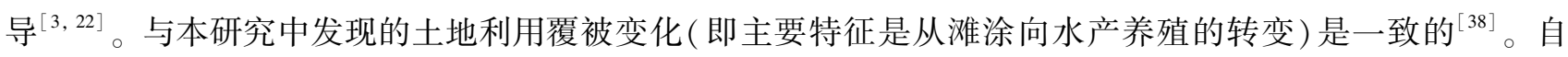
1978 年中国迎来 “改革开放”, 由国家所有制和中央计划主导的经济转变为以市场为导向的改革,其中包括农 业的去集体化,但在 1992 年前的改革初期,早期的填海围剭行动主要是由沿海地区的地方政府主导进行。因 此, 湿地围垦规模相对较小, 甚至在 1980 年代后期有所减少, 这主要是由于政府认为围垦的边际效益在缩小, 开垦的意愿有所降低 (图 4)。自 1980 年代末期至 1990 年代末, 中国改革开放力度进一步加大, 涉及许多国 有工业的私有化和承包制以及价格管制的取消。与此同时,农业采用了家庭联产承包责任制。随后, 中国成 为世界上增长最快的经济体, 1992 年以来, 人均 GDP 增长了约 23 倍。经济的快速增长, 加上农业和农村的改 革鼓励和促进了个体在沿海地区的投资,进而促进了滩涂围剭规模的迅速扩大。江苏沿海优越的地理环境条 件和传统的养殖技术造就了大规模的水产养殖池塘, 江苏也成为中国重要的水产养殖基地。渔业产出在江苏 省农业总产值中的比例从 1988 年的 $8 \%$ 增加到 2018 年的 $24 \%{ }^{[39]}$ 。

\section{2 滩涂开发利用与生态保护等环境政策影响}

江苏沿海滩涂开发历史悠久,尤其到近代,沿海滩涂围层逐渐成为全方位,多部门的综合性大开发,投资 大, 影响因素复杂, 不仅受社会经济发展影响,亦受滩涂开发利用政策引导及生态环境保护政策影响。早在 20 世纪 90 年代江苏提出 “海上苏东”计划, 涉及包括盐城、南通和连云港 3 个地级市和 24 个县 (市、区), 是长 江三角洲的重要组成部分, 区位优势独特, 土地后备资源丰富,战略地位重要。2009年国务院通过《江苏沿海 地区发展规划》, 江苏沿海大开发被上升为国家战略。对比过去沿海发展更多局限于海洋本身的产业, 如养 殖业等, 近年实施沿海开发战略, 突出强调沿海制造业和临港产业带的建设, 强调江苏的沿海产业带不应仅限 于农业带, 更为重要的是工业带, 突出发展包括物流在内的现代服务业。依据功能定位不同, 沿海滩涂围垦方 向及强度亦不相同。如盐城滨海县和大丰区, 南通如东、海门和启东县等, 功能定位为现代化沿海港口群, 以 战略新兴产业、临港产业为主体的先进制造业基地和现代服务业基地, 其滩涂利用以大丰港、如东经济开发区 等港口及经济开发区建设为主; 而盐城响水县、射阳县和东台市, 南通海安县等功能定位为重要海洋生态功能 维护区、海洋水产品供给的重要保障区、生态养殖示范区, 在该区域重点海洋生态功能区严格限制不符合保护 目标的开发活动,不得擅自改变海岸、海底地形地貌及其他自然生态环境状况。

长期的高强度围星在促进经济急剧增长的同时也引起一系列生态问题。我国于 1950 年代和 1980 年代 分别进行了两次全面的沿海调查以查清滩涂资源。也正是从那时起, 江苏沿海建立了许多自然保护区(如江 苏盐城湿地国家级自然保护区) 并制定了相关规定 (《江苏省滩涂开发利用管理办法》)。然而,围垦带来的巨 大经济回报, 以及保护执行不到位促使地方政府绕开相关法规,湿地围旺仍在持续增长。尤其是我国执行严 格的耕地保护政策, 规定“占一补一”, 对于沿海城市来说, 滩涂围垦是实现这一动态平衡的最佳途径。2011 年, 国务院提出 “生态红线”, 并将 $5.33 \times 10^{7} \mathrm{hm}^{2}$ 湿地红线确定为中国生态文明发展的重要组成部分, 在全国范 围内由上至下各级政府采取了一系列措施加强环境保护。虽然保护资源的形势严峻,同时也取得了一些立笔 见影的效果, 即国家环境保护政策的加强扼制了滩涂围层的高速增长 (图 4)。

此外,经过几十年的高强度围乍,苏北沿海剩余滩涂接近或低于平均海平面,导致开发成本高昂,经济回 报低,这可能是滩涂围层速率放缓的另一重要原因。

\section{3 不确定性分析}

首先,遥感数据是离散的,间隔为 $2-3$ 年, 因此解译得到景观变化并非连续的。而滩涂围怎是一项持续 且不断演化的过程,这中间可能导致一些围层信息缺失。其次, 尽管目前国内外已经开展大量围绕 EKC 模型 
的实证研究,但是,关于 $\mathrm{EKC}$ 的假设共识尚未完全达成。具体而言,将环境退化作为一个内生变量,将人均 GDP 作为一个外生变量, 其模型模拟的结果有可能是混淆的 ${ }^{[40]}$ 。此外, 由于不同时期经济数据统计口径不 同,虽经过一致性转换,仍可能存在一定误差。

\section{6 结论}

研究揭示了 1980-2018 年江苏沿海地区滩涂主要变化特征,并基于 EKC 模型探讨了滩涂围层与经济发 展的耦合关系。研究结果显示,养殖水体扩张是近 40 年江苏滩涂景观变化的主要特征;相比养殖水体聚集发 展的盐城市, 以启东为典型代表的南通市经历了相对较完整的养殖水体的滩涂围垦过程, 其养殖水体面积与 区域渔业产值存在指数关系, 即当人均地区产值达到约 9.55 万元时, 区域渔业产值的增长不再以通过围垦的 养殖水体扩张为主要途径; 江苏沿海滩涂围艮与经济发展之间存在典型倒 $\mathrm{U}$ 型曲线关系。滩涂围剭可分为 3 个阶段,初期阶段 (1980-2005 年), 滩涂围剭随着经济发展而急剧增加, 滩涂围剭速度约为 $108.13 \mathrm{~km}^{2} / \mathrm{a}$, 单 位滩涂围层与人均 GDP 增长关系为 4.11 元 $/ \mathrm{km}^{2}$ 。转折点出现在中期 (2005-2014 年), 人均 GDP 约为 $3.64 \times$ $10^{4}$ 元, 此阶段滩涂围剭平均速率为 $146.34 \mathrm{~km}^{2} / \mathrm{a}$, 滩涂围剭与人均 GDP 增长的关系为 17.08 元 $/ \mathrm{km}^{2}$ 。后期 (2014-2018 年), 滩涂围层随着经济发展呈现下降趋势, 人均国内生产总值高达 $7.37 \times 10^{4}$ 元人民币以上, 滩 涂围垦约为 $76.35 \mathrm{~km}^{2} / \mathrm{a}$, 滩涂围垦与人均 GDP 增长的关系增加至 60.77 元 $/ \mathrm{km}^{2}$ 。3 个阶段中, 单位滩涂围层 与人均 GDP 增长呈显著增加的趋势。经济发展、农业和农村经济改革以及国家和地方各级政策均对滩涂围 垦具有重要影响。严格的国家环境保护政策将是控制滩涂围垦、保护生态环境的重要手段。

\section{参考文献 (References) :}

[ 1 ] 陈吉余. 开发浅海滩涂资源拓展我国的生存空间. 中国工程科学, 2000, 2(3): 27-31.

[ 2 ] Halpern B S, Walbridge S, Selkoe K A, Kappel C V, Micheli F, D'Agrosa C, Bruno J F, Casey K S, Ebert C, Fox H E, Fujita R, Heinemann D, Lenihan H S, Madin E M P, Perry M T, Selig E R, Spalding M, Steneck R, Watson R. A global map of human impact on marine ecosystems. Science, 2008, 319(5865) : 948-952.

～ 3 ] 沈永明, 冯年华, 周勤, 刘咏梅, 陈子玉. 江苏沿海滩涂围圼现状及其对环境的影响. 海洋科学, 2006, 30( 10) : 39-43.

[ 4 ] 刘彦随, 李进涛. 近 30 年中国沿海围剭土地利用格局及其驱动机制. 中国科学: 地球科学, 2020, 50(6): 761-774.

[ 5 ] Chambers L G, Steinmuller H E, Breithaupt J L. Toward a mechanistic understanding of “peat collapse” and its potential contribution to coastal wetland loss. Ecology, 2019, 100(7): e02720.

[ 6 ] Davidson N C. How much wetland has the world lost? Long-term and recent trends in global wetland area. Marine and Freshwater Research, 2014, 65(10): 934-941.

[ 7 ] 李加林, 杨晓平, 童亿勤. 潮滩围县对海岸环境的影响研究进展. 地理科学进展, 2007, 26(2): 43-51.

[ 8 ] 徐彩瑶, 兴励杰, 朱明. 沿海滩涂围怎对生态环境的影响研究进展. 生态学报, 2018, 38(3): 1148-1162.

[ 9 ] Zhang J Y, Ma K M, Fu B J. Wetland loss under the impact of agricultural development in the Sanjiang Plain, NE China. Environmental Monitoring and Assessment, 2010, 166(1/4): 139-148.

[10] Kennish M J. Environmental threats and environmental future of estuaries. Environmental Conservation, 2002, 29(1): $78-107$.

[11] Stein E D, Doughty C L, Lowe J, et al. Establishing targets for regional coastal wetland restoration planning using historical ecology and future scenario analysis: the past, present, future approach. Estuaries and Coasts, 2020, 43(2): 207-222.

[12] Airoldi L, Beck M W. Loss, status and trends for coastal marine habitats of Europe.//Gibson R N, Atkinson R J A, Gordon J D M eds. Oceanography and Marine Biology: An Annual Review, Florida: Routledge \& CRC Press, 2007, 45: 345-405.

[13] 温馨燃, 王建国, 王雨婷, 刘志川, 王明常. 1985-2017 年环渤海地区围填海演化及驱动力分析. 水土保持通报, 2020, 40(2): 85-91, 99.

[14] Guerra A, de Oliveira P T S, de Oliveira Roque F, Rosa I M D, Ochoa-Quintero J M, Guariento R D, Colman C B, Dib V, Maioli V, Strassburg B, Garcia L C. The importance of Legal Reserves for protecting the Pantanal biome and preventing agricultural losses. Journal of Environmental Management, 2020, 260: 110128.

[15] 曹善浩, 王志强, 刘贤赵, 魏俊锋, 林剑. 1956 年以来 9 个时期湖南省湿地动态研究. 湿地科学, 2020, 18(1) : 54-61.

[16] 方仁建, 沈永明. 围垦对海滨地区景观演变及其质心移动的影响一以盐城保护区部分区域为例. 自然资源学报, 2015, 30( 5) : 772-783. 
[17] 廖华军, 李国胜, 王少华, 崔林林, 欧阳宁雷. 近 30 年苏北滨海滩涂湿地演变特征与空间格局. 地理科学进展, 2014, 33(9)： 1209- 1217.

[18] 间晓露, 钟敬秋, 韩增林, 孙才志, 刘氷. 近 40 年辽东湾北部围旺区内外滨海湿地景观演替特征及驱动力分析. 地理科学, 2019,39 (7) : $1155-1165$.

[19] 张健, 施青松, 黄宝兴. 围腛的社会经济价值及其对海洋环境影响的评估. 海洋学研究, 2006, 24(S1): 20-25.

[20] Xu C, Sheng S, Zhou W, Cui L J, Liu M S. Characterizing wetland change at landscape scale in Jiangsu province, China. Environmental Monitoring and Assessment, 2011, 179(1/4): 279-292.

[21] 间文文, 谷东起, 王勇智, 吴桑云, 丰爱平, 明洁. 盐城海岸带湿地景观演变分析. 中国海洋大学学报, 2012, 42(12): 130- 137.

[22] Wang C, Wang G, Guo Z R, Dai L J, Liu H Y, Li Y F, Chen H, Zhao Y X, Zhang Y N, Cheng H. Effects of land-use change on the distribution of the wintering red-crowned crane (Grus japonensis) in the coastal area of northern Jiangsu Province, China. Land Use Policy, 2020, 90: 104269.

[23] 方仁建, 沈永明, 时海东. 基于围良特征的海滨地区景观格局变化研究一以盐城海岸为例. 生态学报, 2015, 35(3): 641-651.

[24] 李建国, 兴励杰, 徐彩瑶, 陈新建, 张云峰, 蔡芳芳. 1977-2014 年江苏中部滨海湿地演化与围苲空间演变趋势. 地理学报, 2015, 70 (1) : 17-28.

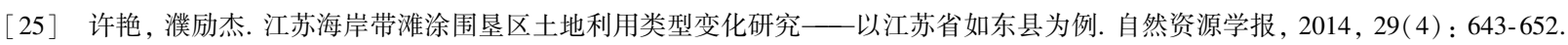

[26] 张长宽, 陈君, 林康, 丁贤荣, 袁汝华, 康彦彦. 江苏沿海滩涂围剭空间布局研究. 河海大学学报: 自然科学版, 2011, 39(2): 206-212.

[27］欧维新, 杨桂山, 于兴修, 李恒鹏. 盐城海岸带土地利用变化的生态环境效应研究. 资源科学, 2004, (3): 76-83.

[28] 张晓祥, 严长清, 徐盼, 戴爆暄, 晏王波, 丁贤荣, 朱晨㬢, 梅丹丹. 近代以来江苏沿海滩涂围脣历史演变研究. 地理学报, 2013, 68 (11) : 1549-1558.

[29］李行, 张连蓬, 姬长晨, 刘红樱, 黄巧华. 基于遥感和 GIS 的江苏省海岸线时空变化. 地理研究, 2014, 33(3): 414-426.

[30] Dinda S. Environmental kuznets curve hypothesis: a survey. Ecological Economics, 2004, 49(4) : 431-455.

[31］张庆宇, 张雨龙, 潘斌斌. 改革开放 40 年中国经济增长与碳排放影响因素分析. 干旱区资源与环境, 2019, 33(10): 9-13.

[32］邹凯波, 曹宝, 张玉虎, 刘晓宇, 孙启宏. 中美两国大气污染与经济增长关系比较分析. 生态经济, 2020, 36(2): 131- 137.

[33] Tsiantikoudis S, Zafeiriou E, Kyriakopoulos G, Arabatzis G. Revising the environmental kuznets curve for deforestation: an empirical study for bulgaria. Sustainability, 2019, 11(16): 4364.

[34] Zhou S, Huang Y F, Yu B F, Wang G Q. Effects of human activities on the eco-environment in the middle Heihe River Basin based on an extended environmental Kuznets curve model. Ecological Engineering, 2015, 76: 14-26.

[35] Getzner M, Kadi J. Determinants of land consumption in Austria and the effects of spatial planning regulations. European Planning Studies, 2020, 28(6): 1095-1117.

[36] Kaika D, Zervas E. The Environmental Kuznets Curve (EKC) theory—part A: concept, causes and the $\mathrm{CO}_{2}$ emissions case. Energy Policy, 2013, 62: 1392-1402.

[37] Saboori B, Sulaiman J. Environmental degradation, economic growth and energy consumption: evidence of the environmental Kuznets curve in Malaysia. Energy Policy, 2013, 60: 892-905.

[38] Duan Y Q, Li X, Zhang L P, Liu W, Liu S A, Chen D, Ji H Y. Detecting spatiotemporal changes of large-scale aquaculture ponds regions over 1988-2018 in Jiangsu Province, China using Google Earth Engine. Ocean \& Coastal Management, 2020, 188: 105144.

［39］农业农村部渔业渔政管理局，全国水产技术推广总站，中国水产学会. 中国渔业统计年鉴. 北京: 中国农业出版社, 1998-2018.

[40] Soytas U, Sari R, Ewing B T. Energy consumption, income, and carbon emissions in the United States. Ecological Economics, 2007, 62(3/4) : 482-489. 